\author{
Geert Meyfroidt \\ Pierre-Edouard Bollaert \\ Paul E. Marik
}

\section{Acute ischemic stroke in the ICU: to admit or not to admit?}

Received: 1 April 2014

Accepted: 1 April 2014

Published online: 8 April 2014

(C) Springer-Verlag Berlin Heidelberg and ESICM 2014

G. Meyfroidt (『)

Intensive Care Medicine, KU Leuven, Line 1: UZ Leuven, 3000 Louvain, Belgium

e-mail: geert.meyfroidt@uzleuven.be

P.-E. Bollaert

Service de Réanimation Médicale, CHU de Nancy, Nancy, France

P. E. Marik

Eastern Virginia Medical School, Norfolk, VA, USA

Acute ischemic stroke (AIS) is an important health-care problem worldwide, and a significant cause of disability as well as mortality. The incidence of AIS is expected to increase in the future, because the majority of AIS are caused by cardio-embolic disorders and atherosclerosis, typical for the ageing population.

Only two interventions in small subsets of patients have been demonstrated to improve the outcome of AIS patients. The single most important intervention to alter the natural history of AIS and improve the patients' functional outcome is the timely administration of a thrombolytic agent (intravenous rt-PA) in the appropriate patient within the narrow 4.5-h window [1]. Endovascular therapy represents an alternative therapy to intravenous rt-PA in those who are not candidates for intravenous rt-PA, but has no advantage over intravenous rt-PA [2]. Hemispheric decompression in patients less than 60 years of age with malignant middle cerebral artery territory (MCA) infarction and space-occupying brain oedema has been demonstrated to improve outcome. This result was confirmed in an individual patient meta-analysis, demonstrating a marked improvement in neurological recovery and survival [3]. For the age group older than 60 years of age with malignant MCA infarction, who are over-represented in the AIS patient group, the recently published DESTINY II trial was able to demonstrate that decompression was also able to reduce mortality, but not influence the proportion of patients with severe disability [4]. Despite initial promise, neuroprotective agents have failed to show a benefit in the management of AIS [5], as have tight glycaemic control [6], high dose albumin [7] and the use of anti-hypertensive agents [8, 9].

Today, increasing numbers of patients with AIS are admitted to an intensive care unit (ICU) for various indications. In this issue of Intensive Care Medicine, Kirkman et al. present a state of the art review of the ICU management of patients with AIS [10]. Their review is very thorough and provides key recommendations on the aforementioned interventions. Unfortunately, they were not able to provide much evidence-based guidance as to which patients should be admitted to the ICU, and which subgroups of AIS patients could actually benefit from ICU management. The guidelines of the Society of Critical Care Medicine state that "in general ICUs should be reserved for those patents with reversible medical conditions who have a reasonable prospect of substantial recovery" [11]. Inherent in this guideline as it applies to the AIS patient, is the assumption that the intensivist has an arsenal of therapeutic interventions which will alter the course of the patient's stroke and that these interventions will improve the patient's outcome. If we take a look at the data on mechanical ventilation in AIS patients, probably one of the main indications for referral to an ICU, not surprisingly, the requirement for mechanical ventilation in itself appears to be associated with both a higher short- and long-term mortality. Using a large administrative database covering 93 counties in the eastern half of the USA, Golestanian et al. [12] evaluated the outcomes of 31,301 AIS patients. The 30-day and 1-year mortality was $64 \%$ and $81 \%$ respectively in those patients who required mechanical ventilation compared to $16 \%$ and $35 \%$ in those patients who did not require mechanical ventilation. A number of smaller studies (less than 100 patients each) have addressed this question as well. These studies confirmed the observed high 
Fig. 1 One-year mortality in stroke patients according to the cause of mechanical ventilation

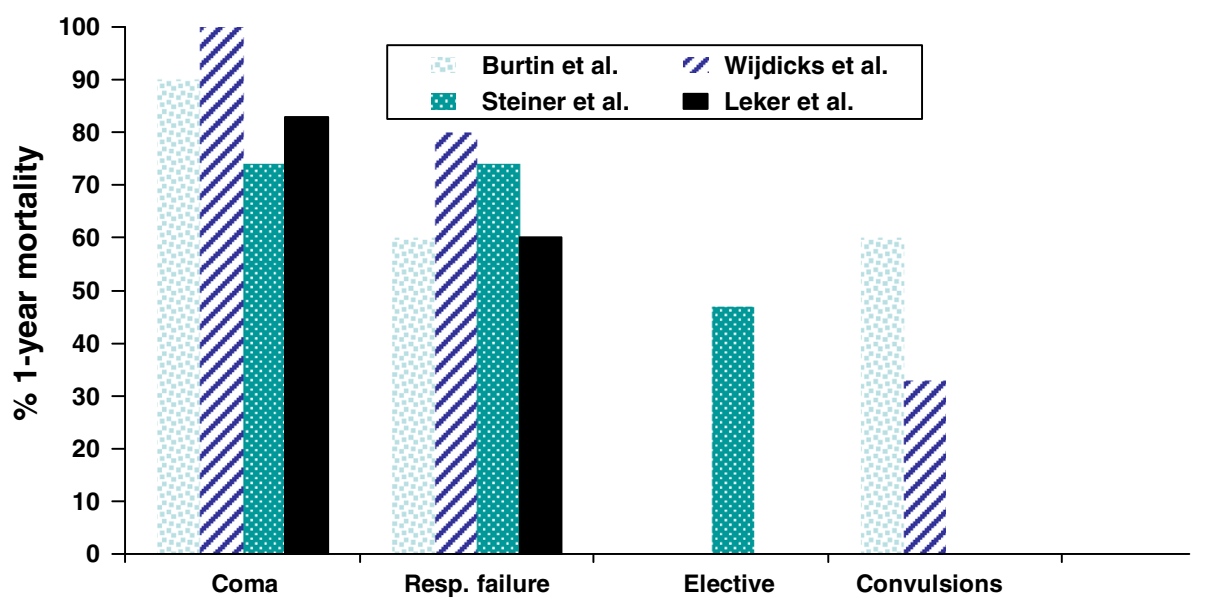

1-year mortality for patients requiring mechanical ventilation, 37-87 \%, with no clear evidence of improvement over time [13-18]. Furthermore, severe disability was observed in $20-45 \%$ of survivors. In this discussion on the benefit of mechanical ventilation for the outcome of AIS, the reason why mechanical ventilation was initiated might be important. Unfortunately, this was only assessed in four of these studies (Fig. 1) [13-16]. Although the population samples included in the latter studies were small, these data suggest that those patients intubated and ventilated for coma or neurologic deterioration may not benefit from mechanical ventilation.

The lack of data on the outcome benefit of specific therapeutic interventions to improve the outcome of the majority of patients suffering from AIS certainly does not imply that physicians should adopt a fatalistic approach when managing these patients. A number of well-conducted clinical trials have demonstrated that the mortality and functional recovery of patients following a stroke are significantly improved when these patients are cared for in a specialized stroke unit as compared to a general medical ward [19,20]. These units provide specialized nursing care and a well-organized multidisciplinary rehabilitation program. Stroke unit care reduces the medical complications in these patients and allows for earlier and more intense rehabilitation.

In contrast to this, specific stroke ICUs were abandoned in the 1970s after it was demonstrated that such units had very little impact on the outcome of patients following a stroke. Nevertheless, a proportion of patients who suffer from stroke may benefit from admission to the ICU. Endotracheal intubation and mechanical ventilation should be reserved for patients with reversible respiratory failure who are likely to have a good prognosis for a functional recovery, e.g. in the treatment and prevention of aspiration pneumonia due to temporal loss of bulbar function, occurring in 37-78\% of stroke patients [21]. Large MCA strokes who may require decompressive craniectomy, regardless of their age [3, 4], and spaceoccupying cerebellar infarctions accessible to a prompt surgical decompression [22] are a clear indication for ICU admission. In some cases, the management of blood pressure, or seizures, might necessitate an ICU admission.

Further research should focus on the use of validated stroke severity scoring systems such as the NIH Stroke Scale (NIHSS) or the Triage Stroke Panel (MMX), taking into account the initial clinical evolution of these patients [23], to identify those patients who will benefit from ICU referral. It is clear that aggressive medical measures in deeply comatose patients, with a low probability of a favourable outcome are a form of non-beneficial care, which will only increase the burden on patients, families and the health-care system. The paradigm of "less may be more" would appear to be appropriate for these patients [24].

\section{References}

1. Lees KR, Bluhmki E, von KR, Brott TG, Toni D, Grotta JC, Albers GW, Kaste M, Marler JR, Hamilton SA, Tilley BC, Davis SM, Donnan GA, Hacke W (2010) Time to treatment with intravenous alteplase and outcome in stroke: an updated pooled analysis of ECASS, ATLANTIS, NINDS, and EPITHET trials. Lancet 375:1695-1703
2. Ciccone A, Valvassori L, Nichelatti M, Sgoifo A, Ponzio M, Sterzi R, Boccardi E (2013) Endovascular treatment for acute ischemic stroke. N Engl J Med 368:904-913
3. Vahedi K, Hofmeijer J, Juettler E, Vicaut E, George B, Algra A, Amelink GJ, Schmiedeck P, Schwab S, Rothwell PM, Bousser MG, van der Worp HB, Hacke W (2007) Early decompressive surgery in malignant infarction of the middle cerebral artery: a pooled analysis of three randomised controlled trials. Lancet Neurol 6:215-222 
4. Jüttler E, Unterberg A, Woitzik J, Bösel J, Amiri H, Sakowitz OW, Gondan M, Schiller P, Limprecht R, Luntz S, Schneider H, Pinzer T, Hobohm C, Meixensberger J (2014) Hacke W for the DESTINY II Investigators. Hemicraniectomy in older patients with extensive middle cerebral artery stroke. N Eng J Med 370:1091-1100

5. Ginsberg MD (2008) Neuroprotection for ischemic stroke: past, present and future. Neuropharmacology 55:363-389

6. Rosso C, Corvol JC, Pires C, Crozier S, Attal Y, Jacqueminet S, Deltour S, Multlu G, Leger A, Meresse I, Payan C, Dormont D, Samson Y (2012) Intensive versus subcutaneous insulin in patients with hyperacute stroke: results from the randomized INSULINFARCT trial. Stroke 43:2343-2349

7. Ginsberg MD, Palesch YY, Hill MD, Martin RH, Moy CS, Barsan WG, Waldman BD, Tamariz D, Ryckborst KJ (2013) High-dose albumin treatment for acute ischaemic stroke (ALIAS) part 2: a randomised, double-blind, phase 3, placebo-controlled trial. Lancet Neurol 12:1049-1058

8. He J, Zhang Y, Xu T, Zhao Q, Wang D, Chen CS, Tong W, Liu C, Xu T, Ju Z (2014) Effect of immediate blood pressure reduction on death and major disability in patients with acute ischemic stroke: the CATIS randomized clinical trial. JAMA 311:479-489

9. Hankey GJ (2011) Lowering blood pressure in acute stroke: the SCAST trial. Lancet 377:696-698
10. Kirkman MA, Citerio G, Smith M (2014). The intensive care management of acute ischemic stroke: an overview. Intensive Care Med. doi: 10.1007/s00134-014-3266-z

11. Task Force of the American College of Critical Care Medicine, Society of Critical Care Medicine (1999) Guidelines for intensive care unit admission, discharge, and triage. Crit Care Med 27:633-638

12. Golestanian E, Liou JI, Smith MA (2009) Long-term survival in older critically ill patients with acute ischemic stroke. Crit Care Med 37:3107-3113

13. Burtin P, Bollaert PE, Feldmann L, Nace L, Lelarge P, Bauer P, Larcan A (1994) Prognosis of stroke patients undergoing mechanical ventilation. Intensive Care Med 20:32-36

14. Steiner T, Mendoza G, De Georgia M, Schellinger P, Holle R, Hacke W (1997) Prognosis of stroke patients requiring mechanical ventilation in a neurological critical care unit. Stroke 28:711-715

15. Wijdicks EF, Scott JP (1997) Causes and outcome of mechanical ventilation in patients with hemispheric ischemic stroke. Mayo Clin Proc 72:210-213

16. Leker RR, Ben-Hur T (2000) Prognostic factors in artificially ventilated stroke patients. J Neurol Sci 176:83-87

17. Santoli F, De JB, Hayon J, Tran B, Piperaud M, Merrer J, Outin H (2001) Mechanical ventilation in patients with acute ischemic stroke: survival and outcome at one year. Intensive Care Med 27:1141-1146
18. Navarrete-Navarro P, Rivera-Fernandez R, Lopez-Mutuberria MT, Galindo I, Murillo F, Dominguez JM, Munoz A, Jimenez-Moragas JM, Nacle B, Vazquez-Mata G (2003) Outcome prediction in terms of functional disability and mortality at 1 year among ICU-admitted severe stroke patients: a prospective epidemiological study in the south of the European Union (Evascan Project, Andalusia, Spain). Intensive Care Med 29:1237-1244

19. Stroke Unit Trialists' Collaboration (2013) Organised inpatient (stroke unit) care for stroke. Cochrane Database Syst Rev 9:CD000197

20. Langhorne P, de Villiers L, Pandian JD (2012) Applicability of stroke-unit care to low-income and middle-income countries. Lancet Neurol 11:341-348

21. Martino R, Foley N, Bhogal S, Diamant N, Speechley M, Teasell R (2005) Dysphagia after stroke: incidence, diagnosis and pulmonary complications. Stroke 36:2756-2763

22. Juttler E, Schweickert S, Ringleb PA, Huttner HB, Kohrmann M, Aschoff A (2009) Long-term outcome after surgical treatment for space-occupying cerebellar infarction: experience in 56 patients. Stroke 40:3060-3066

23. Brouns R, Sheorajpanday R, Kunnen J, De Surgeloose D, De Deyn PP (2009) Clinical, biochemical and neuroimaging parameters after thrombolytic therapy predict long-term stroke outcome. Eur Neurol 62(1):9-15

24. Knox M, Pickkers P (2013) "Less is more" in critically ill patients: not too intensive. JAMA Intern Med 173:1369-1372 